\title{
DESIGN PRINCIPLES FOR DEVELOPING STATISTICAL LITERACY IN MIDDLE SCHOOLS
}

\author{
CHRISTIAN BÜSCHER \\ TU Dortmund University, Germany \\ christian.buescher@tu-dortmund.de
}

\begin{abstract}
Statistical literacy is a skill required of all well-educated citizens and is conceptualized here as not only the ability to read given statistical information, but also the ability to imagine the often unreported data and underlying assumptions of this information. While these competencies can be developed as early as middle school, only limited insights exist about how this can be done. At this level statistics is commonly seen as only a small part of mathematics curriculum. Therefore, highly focused didactic materials and design principles for use in middle school are needed. The design research study described here began with principles for developing statistical literacy associated with investigating conflicting statistical information about critical contexts like climate change through the use of digital tools. Student responses from an online course show that the design principles can be used to develop statistical literacy in middle schools. Limitations of the materials described are used to propose directions for future design research studies regarding developing statistical literacy.
\end{abstract}

Keywords: Statistics education research; Statistical literacy; Design principles; Learning trajectory; Design research; Critical literacy

\section{INTRODUCTION}

\subsection{STATISTICAL LITERACY IN MIDDLE SCHOOLS}

Following trends of digitalization in school, conceptualizations of statistical literacy that place an emphasis on citizens' abilities to critically evaluate data and uncertainty are playing an increasingly important role in education discourse (Gould, 2017; Wild, 2017). These conceptualizations are manifested in the PISA 2022 mathematics framework, which includes a strengthened role of data and uncertainty for argumentation and decision making (Organisation for Economic Co-operation and Development, 2018). The stated aims, "students are encouraged to engage with data based arguments with awareness of the limitations of the conclusions that can be drawn" (p. 19) and "students should be expected to appreciate how the formulation of the analysis in a model impacts the conclusions that can be drawn" (p. 27), show the high critical demand for literacy regarding data and uncertainty expected even in middle schools.

In statistics education research, these demands have long been addressed through the construct of statistical literacy ( $\mathrm{Gal}, 2002)$, which is currently undergoing lively discussion about integrating modern domains like big data and machine learning (François et al., 2020; Prodromou \& Dunne, 2017;). Researchers in statistics education have not been content with only formulating goals for statistical literacy. They have also begun to find ways to measure or increase the statistical literacy of students (Budgett \& Rose, 2017; Callingham \& Watson, 2017; Jones \& Goldring, 2017; Krishnan, 2015; Sabbag et al., 2018). The research undertaken resonates with recent calls to increase attention on providing constructive ways to develop all types of statistical knowledge by identifying learning trajectories and design principles for didactic materials (Arnold et al., 2018; Ben-Zvi et al., 2018).

When design and research work about statistical literacy has been carried out, however, it has been situated mostly in later stages of formal education (e.g., Budgett \& Rose, 2017; Jones \& Goldring, 2017). Regarding the development of statistical literacy in middle schools, there seems to be a longstanding research gap (Callingham \& Watson, 2017; Carmichael et al., 2009). The relatively few empirical results indicate that statistical literacy is low in some countries (Yolcu, 2014) or seems to plateau at a level of mostly non-critical understanding of statistics for which Callingham and Watson

Statistics Education Research Journal, 21(1), Article 8. https://doi.org/10.52041/serj.v21i1.80

(C) International Association for Statistical Education (IASE/ISI), February 2022 
(2017) observe, "little seems to have changed during the 10 years between the various studies" (p. 191). Consolidated design principles, such as the principle of growing samples (Bakker \& Gravemeijer, 2004), which have been implemented in a wide range of teaching-learning arrangements, including the middle school setting, have proven very effective for developing statistical reasoning and informal statistical inference, but have not been extended to statistical literacy.

This necessitates research that illuminates pathways to statistical literacy in regular middle school classrooms. Because in many countries statistics education in middle school mostly takes place in mathematics classrooms with very limited time allocated to statistics (Zieffler et al., 2018), these pathways require a sharp focus on a few important aspects of statistical literacy. Such a concern was also formulated by Wild (2017), who warned of overly complex specifications of learning goals: "unless the number of such lessons [about statistical literacy] is small, no one will ever be able to remember and apply them" (p. 31). Work remains not only on identifying a suitable set of small lessons about statistical literacy, but also on the design and research of didactic materials for developing statistical literacy.

\subsection{CONSIDERATIONS ON THE RESEARCH APPROACH}

Because statistics instruction varies greatly across different countries (Zieffler et al., 2018), care must be given so that investigated approaches for developing statistical literacy are not applicable only to individual school contexts. Design research methodologies address this issue by grounding materials developed in substantial theory development (Prediger, 2019; Prediger et al., 2015). A central characteristic of design research is the theory developed has to do real work (Bakker \& van Eerde, 2015). The work has to be both content-specific, in order to be applicable, as well as transferable, meaning "general enough to be applicable in different contexts such as classrooms in other schools in other countries" (Bakker \& van Eerde, 2015, p. 438). This often necessitates finding new theoretical constructs that re-frame the learning content in order to identify the connections between theoretical goals, designed materials, and observed student thinking (Hußmann \& Prediger, 2016).

One common theoretical device used for this task is the design of a hypothetical learning trajectory, learning trajectory, or learning progression (Bakker \& van Eerde, 2015; Clements \& Sarama, 2004). Although the exact definitions vary, these constructs generally refer to theory elements comprising the specification of learning goals, of tasks or activities aimed at these goals, and a hypothesized or empirically reconstructed progression of student thinking. Transferability can be increased by illustrating underlying design principles, which explicate the theoretical and empirical justifications and the exact mechanisms behind the didactic materials, which can be considered a major contribution of design research (van den Akker, 1999).

This study provides a contribution towards the goal of developing statistical literacy in middle schools by pursuing these research questions:

RQ1: How can the learning content of statistical literacy be structured in a way that allows the design of focused didactic materials for developing statistical literacy?

RQ2: What are transferable design principles for developing statistical literacy in middle schools?

An answer addressing RQ1 is given by providing a theoretical model that specifies the learning content of statistical literacy (Section 2). Concerning RQ2, design principles for developing statistical literacy are elaborated (Section 3) and a detailed and theory-based analysis of developed learning materials that implement these design principles is given (Section 4). Accompanying empirical results lend some plausibility to the claims that the identified design principles are useful for developing statistical literacy (also Section 4). The paper concludes with a proposed learning trajectory building on the design principles. Regarding the twin tasks of design and research, this paper leans more to development of theory and design rather than extensive empirical research, and the empirical results presented here fulfill a more illustrative role. The main contribution this paper provides is theoretical: namely the specification of transferable design principles for developing statistical literacy, accompanied by an empirical illustration of their working mechanisms. 


\section{LEARNING GOALS FOR STATISTICAL LITERACY}

There is no single definition of statistical literacy in the research discourse. Still, a commonly used distinction to characterize statistical literacy is that of the roles of data consumers and data producers (Gal, 2002). The former relates to the use of statistics to interpret data, whereas the latter concerns the "basic and important skills that may be used in understanding statistical information or research results" (Ben-Zvi \& Garfield, 2004, p. 7). It is argued that in today's data-drenched society, statistical literacy becomes a necessity (Steen, 2001; Engel, 2017). Public life is influenced by technologies utilizing (big) data, a fact often unknown to society's participants. Therefore, the ability to recognize the role of data in society and to evaluate data use critically allows citizens to regain agency. Earlier conceptualizations of statistical literacy leaned heavily on the role of the data consumer, whereas there is a growing recognition that statistical literacy also requires an integration of the role of data producer. Researchers such as Weiland (2017) emphasized that "statistical literacy is not just consuming statistics [...], but using statistics as a lens and using a broader reflective lens of the world in dialog, enabling a new view of the world" (p. 39). Engel (2017) proposed statistical literacy as a remedy against the "growing disdain for factual knowledge in the public discourse" (p. 44) that not only entails "being aware of misuse of statistics" (p. 48), but also more actively "knowing ways to overcome [the misuse of statistics]" (p. 48). Conceptualizations of statistical literacy thus need to integrate both roles of consumer and producer in relation to data and all other kinds of statistical information.

\subsection{SELECTIVE AND IMAGINATIVE READING OF STATISTICAL INFORMATION}

A useful model for illuminating the importance of the process of producing statistical information for statistical literacy is the metaphor of distillation and encapsulation employed by Wild and Pfannkuch (1999). Through a cyclic process of interrogating statistical information and their relation to contextual ideas, statisticians "extract essence from inputs, discarding distractions and detail along the way" (p. 233). The result is a highly-condensed idea about a phenomenon encapsulated in statistics-based information. For consistency with the theme of literacy, this distilling and encapsulating are considered a kind of selective reading of statistical information, not in the sense of a biased discounting of inconvenient information, but in the same sense of extracting the relevant core of statistical information without the distractions and unnecessary details.

It is this condensed information that the consumer of statistics has to interpret, which requires the kind of knowledge mapped out by Gal (2002) as the data-consuming side of statistical literacy. For Gal (2002), statistical literacy refers to the "ability to interpret and critically evaluate statistical information" as well as the "ability to discuss or communicate" peoples' reactions to this information (p. 2). On the one hand, this relates to understanding a highly condensed piece of information by drawing on statistical, mathematical, and contextual knowledge. For example, a statistically literate citizen needs to know how to read certain graphs and to understand concepts of center and variability in order to understand the provided statistical information. This also allows the citizen to identify misinformation and even manipulations that are created through faulty use of statistics like conveniently forgetting important information like sampling size or confusing percent change and percent point change (Gal, 2002). On the other hand, Gal also integrated critical questions into his conceptualization of statistical literacy. By asking whether there could be hidden biases in the data generation process, whether the results could be influenced by an unreported skewed distribution, or whether there could be any alternative interpretations, these questions go beyond the condensed statistical information at hand.

This critical reflection of the statistical information is central to statistical literacy ( Callingham \& Watson, 2017; Weiland, 2017). Going back to the metaphor of distilling and encapsulating, distilling statistical information is not a lossless procedure. Some of the distractions and details that are boiled off may actually have been important but are irretrievably lost in the final product. When citizens are faced with a selective reading of data that consists of only an average reported in a newspaper article, they are missing information required for adequately judging the statistical argument. They need to perform a kind of imaginative reading of the provided statistical information by imagining the possible processes of data generation, by anticipating possible distributions, and by hypothesizing about alternative explanations, resonating with the worry questions outlined by Gal (2002). This again shows the interdependency of the roles of producer and consumer of statistical information, as an imaginative 
reading of statistical information requires knowledge of how selective reading of data can impact the conclusions drawn.

\subsection{ACTIVITIES OF SELECTIVE AND IMAGINATIVE READING}

The argument in the previous section is that statistically literate citizens need to be able to engage in selective and imaginative reading of statistical information. This does not yet clarify the knowledge needed to engage in this selective and imaginative reading. As a more focused conceptualization, a model specifying the learning goal of statistical literacy is given in Figure 1, which is explained in the remainder of this section.

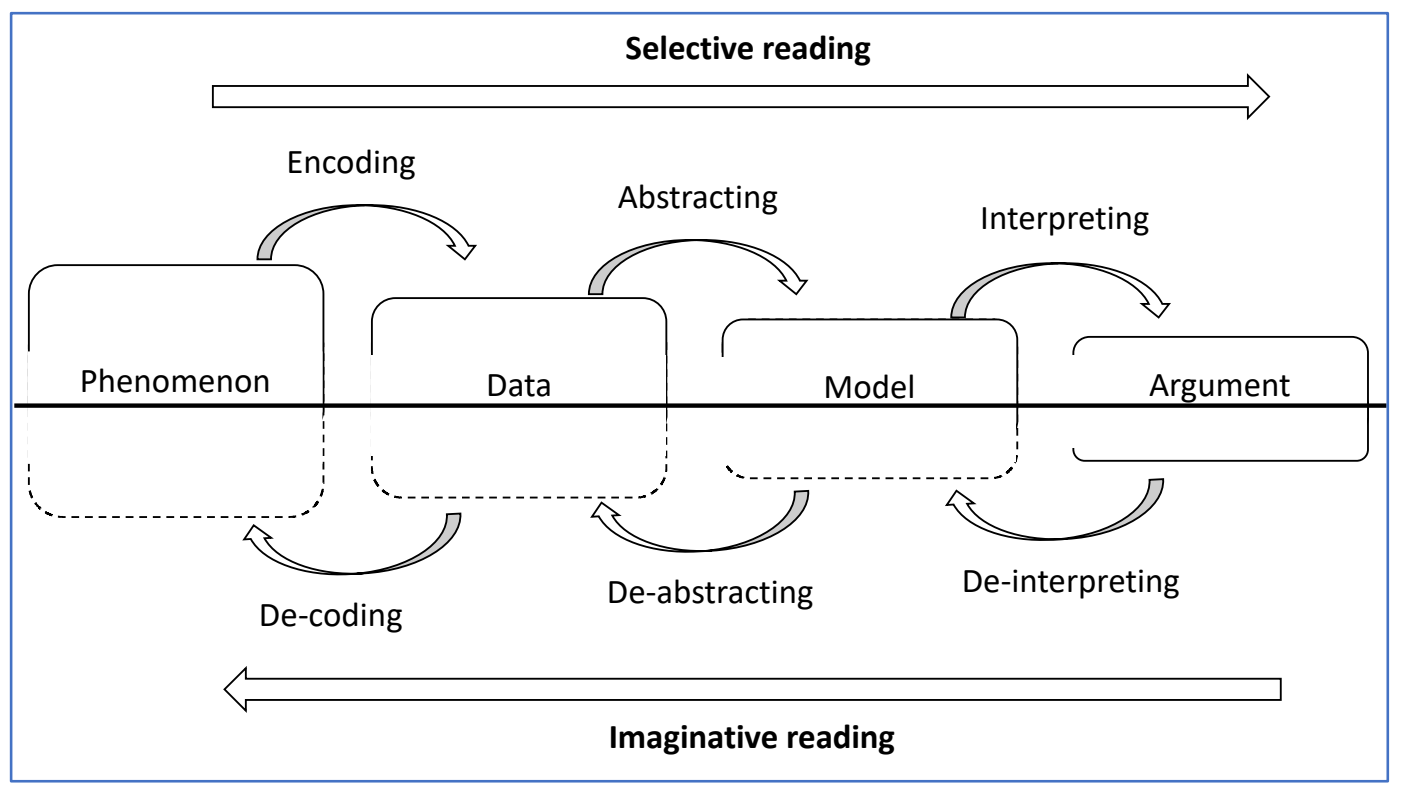

Figure 1. Statistical literacy requires activities of selective and imaginative reading of statistical information

A reader of statistical information can be faced with very different types of information, each of which requires different knowledge to read either selectively or imaginatively. When Wild (2017) emphasized that data can tell lies, he highlighted the differences between the phenomenon that is to be investigated and the data that are supposed to represent it, but do not always do so truthfully. Concerned with more recent trends like machine learning, Grant (2017) focused on the role of statistical models and posited "the statistically literate user might wonder whether such a model has produced an unbiased answer" (p. 19). It might very well be the case that the model reflects an unknown bias, a major concern for big, messy data. Thus, he produced questions that concern the relationship between the data and a model. Finally, Gal (2002) required the statistically literate citizen to understand that "messages may be created to convince the reader or listener to adopt a specific point of view or reject another, and hence may use one-sided arguments or present selective information" (p. 7). Here, a bias is not created by data or model, but rather by the investigator who selectively reads the model. Even if a suitable model was used to investigate data, the argument drawn from it might still be misleading. Every act of selective reading decreases the richness of the statistical information (signified in Figure 1 through progressively smaller boxes). A reader of a statistical argument needs to engage in imaginative reading to intuit this lost richness in order to judge the quality of the argument (signified in Figure 1 through the dashed lines in the lower half).

Engaging in selective and imaginative reading of statistical information then requires different kinds of knowledge, depending on the translation between phenomenon, data, model, or argument (Figure 1). Regarding selective reading, research in statistics education has already thoroughly mapped out this knowledge. Producing data by encoding a phenomenon through measurements or surveys is the basis of any statistical thinking as it satisfies the need for data (Wild \& Pfannkuch, 1999). Statistics education 
research has also produced many investigations into how students create models from data (e.g., Lehrer $\&$ English, 2018). To distinguish this act of model-creation from the whole process of modeling and to emphasize the selective nature of models only representing parts of the data (Lesh \& Lehrer, 2003), this activity is considered abstracting from data to model. Finally, with constructs such as informal inferential reasoning (Makar et al., 2011), research has also illustrated the required knowledge for students to interpret models in order to arrive at a statistical argument.

Imaginative reading of statistical information has seen comparatively little attention but has always been a focus of research on statistical literacy. When faced with a newspaper article containing the statistical argument that "because average household income has increased, poverty has decreased", a statistically literate citizen needs to be able to reverse the interpretation of the model undertaken by the author in an activity denominated here as de-interpreting: the model behind this argument would likely be the mean or median of some distribution. This activity resonates with Gal's (2002) worry questions asking what the numbers in an article actually mean or whether there is enough information provided to estimate the underlying model. The next step in imaginative reading is to hypothesize about the possible data about household income that produced the model in question. Researchers that investigate this activity of de-abstracting show, for example, how students can develop a critical understanding of how different models of data can provide different perspectives on that data (Büscher \& Prediger, 2019). And finally, a statistically literate citizen can evaluate whether the collected household income data is adequate to represent the phenomenon of poverty, reversing the encoding process by de-coding the data. Such considerations resonate with critical approaches to statistical and mathematical literacy (Weiland, 2017).

Thus, the abilities of selective and imaginative reading provide a conceptualization of statistical literacy: students need to master the activities of encoding or decoding, de-abstracting, and deinterpreting. After this work of specifying the learning goals, the next step is to identify design principles that can support the development of statistical literacy.

\section{DESIGN PRINCIPLES FOR DEVELOPING STATISTICAL LITERACY}

\subsection{METHODOLOGY}

This study is part of the cli.math Design Research project at TU Dortmund University in Germany, utilizing the methodological framework of topic-specific Didactical Design Research (Prediger \& Zwetzschler, 2013). Work on cli.math started in early 2020 and continues the work of a design research project carried out from 2014 to 2018 which focused on developing conceptual and reflective knowledge about statistical measures in $7^{\text {th }}$ Grade (Büscher, 2018). The cli.math project broadens the scope of the previous project to include different types of models as well as to increase the focus on imaginative reading of statistical information. In early 2020, the design principles and didactic materials that implement the design principles were developed. Due to the impossibility of classroom research during the COVID-19 pandemic, the materials were then adapted as an online course where students could submit written responses to different tasks. This course consisted of six different teaching units, the first of which will be outlined in Section 4.

\subsection{PARTICIPANTS}

To gain insights into the effects of the design principles, online video interviews were conducted with three students (ages 12,13, and 15) while they worked on the online course. The three students all lived in households in the Dortmund area, but attended different schools. They all volunteered to participate in the study. Prior knowledge of statistics was not controlled. According to German curricular standards, the students should have had lessons on basic statistical concepts like line graphs, median, and mean. These are commonly taught with a very procedural focus on calculating the mean, instead of using the mean to describe the center of distributions. Therefore, it can be expected that the students had not encountered many opportunitities to develop statistical literacy in their previous schooling.

The data collected comprise audio recordings of the interviews as well as the students' written responses in the online course. In this study, only the written answers are used to provide insights into 
the effects of the design principles. Additionally, the written responses of the two students aged 12 and 13 are considered, as they fit the age bracket for $7^{\text {th }}$ Grade in Germany, for which the materials were designed.

\subsection{DESIGN PRINCIPLES}

The didactic materials designed in the project were based on several design principles, each of which contributes to the overall design that supports the development of statistical literacy.

Resolving Conflicting Information. One design principle identified to be beneficial to statistical learning is the elicitation of statistical arguments (Ben-Zvi et al., 2018). This idea was adapted to develop statistical literacy, specifically through the design principle of Resolving Conflicting Information, which is used to provide the structure for lessons. This design principle states that each lesson should introduce, analyze, and resolve a specific conflict created because two pieces of information about the same phenomenon seem to contradict each other. The structure was inspired by the long-standing principle of the "tool-object dialectic" employed in French didactics of mathematics:

a problem is given to the pupils, which has a meaning for them. With their knowledge, they begin to tackle it, but they cannot solve it complete[ly]. The concepts which the learning process is aimed at are the tools suitable for the question. (Douady, 1985, p. 35)

In the Resolving Conflicting Information design principle, the problem faced by the students is not a mathematical problem, but rather a conflict that has arisen because two interlocutors have carried out different selective readings, resulting in different statistical information about the same phenomenon. The investigation of the conflict then proceeds in three stages:

(1) The conflict is introduced in the didactic materials. Students are asked to hypothesize about possible explanations, but are not expected to solve the conflict.

(2) The conflict is analyzed by engaging in statistical investigation. Activities of imaginative reading are elicited: finding the model employed in an argument, analyzing the relationship between the model and the data, or putting the data back into the context of the phenomenon. Possibly, new statistical concepts need to be introduced that provide new tools of analysis for the students.

(3) The conflict is resolved by identifying the point where different selective readings have created different statistical information.

Incomplete Information. In real-life situations, statistical arguments are often provided without explicating the underlying model or data. This is necessary for providing concise communication, but also impedes critical investigation of the argument. In the Incomplete Information design principle, the occlusion of such information is used productively to elicit activities of imaginative reading. Without access to critical information, students are required to hypothesize about this information, which provides opportunities to discuss the incongruences created through different selective readings. For example, if only an argument and data are given, but the model is missing, this could prompt students to reason about models that possibly fit to both the data and the argument. If model and phenomenon are given, but data are missing, this could prompt students to hypothesize about how the data could look, and in what ways they do or do not fit the model. In this way, imaginative readings are elicited.

Critical contexts. Recent statistics education research has called for the use of contexts that enable appreciation of the usefulness of statistics for understanding relevant problems of society (Engel, 2017). Unfortunately, such contexts are rarely utilized in textbooks, and if they are, the critical issues are trivialized (Weiland, 2019). This presents a serious problem, as:

if students are to be statistically literate, they need to have opportunities to engage in making sense of issues that are in the forefront in their societies and to see how statistics can be a powerful lens for evaluating issues and making informed decisions. (Weiland, 2019, p. 35)

Contexts that enable these opportunities are here considered critical contexts, as they emphasize the importance of critical reflection of statistical arguments. Naturally, the simple presence of such a 
context is not enough; instead, the materials need to explicitly call for activities of selective and imaginative readings about critical issues.

Digital Tools. While there is an argument to be made that the ability to draw graphs and calculate means without support of digital tools remains an important learning goal, digital tools do provide great opportunity for the development of statistical reasoning (Biehler et al., 2013). If the basics are understood, digital tools remove much of the busywork of drawing graphs and calculating measures. The same can be true for the development of statistical literacy. It has long been argued that using technological tools allows teaching to focus on deeper conceptual understanding as well as an increased focus on reflecting the mathematics employed (Peschek \& Schneider, 2002). A promising tool for descriptive statistics is the Common Online Data Analysis Platform (CODAP) (Concord Consortium, 2021), which has already been used successfully in statistics education research, including the development of statistical literacy (Poling \& Weiland, 2020). Additionally, the project cli.math aims to provide a contribution for a digital turn in education. The designed materials do not take the form of paper worksheets, but are made available on an online learning platform specifically programmed for the project. The specifics of the digital platform, however, are not the focus of this study.

\section{EFFECTS OF THE DESIGN PRINCIPLES}

In the following section, the effects of the design principles are investigated by illustrating the first teaching unit of the developed didactic materials. The materials follow the steps of the Resolving Conflicting Information design principle: (1) introducing the conflict, (2) analyzing the conflict, (3) resolving the conflict.

\subsection{INTRODUCING THE CONFLICT}

The design introduces the conflict for this lesson by introducing data on the number of "hot days" in Germany and comments made by two people, Pia and Keenan (see Figure 2).

\begin{tabular}{|c|c|c|c|c|c|c|}
\hline \multicolumn{7}{|c|}{$\begin{array}{l}\text { In order to investigate climate change, the German federal weather service counts the number } \\
\text { of hot days in Germany. A day is considered a hot day, if temperatures reach } 30^{\circ} \mathrm{C} \text {. The data is } \\
\text { made available to the public through the German federal weather service. The table lists the } \\
\text { number of hot days of every year in Münster. }\end{array}$} \\
\hline & Decade & Year & Number & Decade & Year & Number \\
\hline & 1990-99 & 1990 & 5 & $2000-09$ & 2005 & 5 \\
\hline & 1990-99 & 1991 & 5 & 2000-09 & 2006 & 14 \\
\hline & $1990-99$ & 1992 & 7 & $2000-09$ & 2007 & 4 \\
\hline & 1990-99 & 1993 & 0 & 2000-09 & 2008 & 7 \\
\hline & 1990-99 & 1994 & 19 & $2000-09$ & 2009 & 5 \\
\hline & 1990-99 & 1995 & 14 & $2010-19$ & 2010 & 14 \\
\hline & 1990-99 & 1996 & 4 & $2010-19$ & 2011 & 4 \\
\hline & $1990-99$ & 1997 & 8 & 2010-19 & 2012 & 8 \\
\hline & 1990-99 & 1998 & 6 & 2010-19 & 2013 & 11 \\
\hline & 1990-99 & 1999 & 11 & 2010-19 & 2014 & 3 \\
\hline & $2000-09$ & 2000 & 5 & $2010-19$ & 2015 & 10 \\
\hline & $2000-09$ & 2001 & 5 & 2010-19 & 2016 & 10 \\
\hline & 2000-09 & 2002 & 6 & $2010-19$ & 2017 & 6 \\
\hline & 2000-09 & 2003 & 17 & 2010-19 & 2018 & 20 \\
\hline & 2000-09 & 2004 & 6 & 2010-19 & 2019 & 18 \\
\hline \multicolumn{4}{|c|}{$\int$ That's always quite different! } & \multicolumn{3}{|c|}{$\begin{array}{l}\text { Well, but generally it's about five } \\
\text { days! }\end{array}$} \\
\hline \multicolumn{4}{|r|}{ - Pia } & \multicolumn{3}{|r|}{ - Kenan } \\
\hline
\end{tabular}

Figure 2. Fictitious students Pia and Kenan disagree whether a pattern can be observed (translated from German) 
In Figure 2, hot days are an indicator for increasing temperatures due to climate change used by the German federal weather service, and are defined as days that reach a maximum temperature of at least $30{ }^{\circ} \mathrm{C}$. This implements the Critical Contexts design principle, as it illustrates the need for providing clear statistics-based messages about the climate. The data used here are sourced from real data from the German city of Münster, made available also by the German Weather Service (Deutscher Wetterdienst, n.d.).

To the trained statistician, it is evident Pia refers to the variability of the data, whereas Kenan refers to the pattern regarding the center. Students of German $7^{\text {th }}$ Grade, however, have no formal training in differentiating between these two concepts. Therefore, the task to explain what Pia and Kenan mean should draw on individual and informal understandings of concepts of variability and pattern, but also reveal any lack of conceptual tools necessary to explain the conflict.

The students working on the task were then prompted to hypothesize about possible explanations for the fictitious students' claims. The following two written answers given by the two students S1 and S2, who worked on the online course, show how this task elicits informal activities of imaginative reading.

S1 The number of hot days in every year is always different, but often it's somewhere around 5 days.

S2 I think that Pia means that every year there are a different number of hot days, sometimes with a lot of difference. And Kenan means that normally it's just around 5 days, or maybe always 5 days difference.

Student 1 mostly repeated the two arguments made by Pia and Kenan. This does not mean that Student 1did not understand the arguments. But this could be taken as indicating that relevant models for de-interpreting the arguments indeed are a learning goal for Student 1. Student 2's response was more eloquent than the answer expressed by Student 1. By proposing that Pia looked at the variable "difference" in hot days from year to year, Student 2 de-interpreted the argument and found a informal model that fitted the data. This student's model of a five-day pattern would not be considered an intended model of climate patterns, however, illustrating a need for new statistical tools.

Next, the students were provided with step-by-step instructions to create line charts in CODAP and tasked with opening the temperature data and creating such a line chart. Line charts are likely to be familiar to students of German $7^{\text {th }}$ Grade, although at this point, the last time they investigated line charts in mathematics was likely in $5^{\text {th }}$ Grade, so it was anticipated their knowledge may have needed to be reactivated. Here, the Digital Tools design principle enables a quick reactivation of this knowledge. Having constructed the line chart, the students were asked to provide the answers to short questions (Figure 3). These questions were intended to reactivate students' knowledge of line charts. They also provided questions that could be used later to evaluate which kind of model should be used to abstract from the data. For example, Question 3 might be more easily answered given a dot plot, whereas the other questions are better suited to line charts.

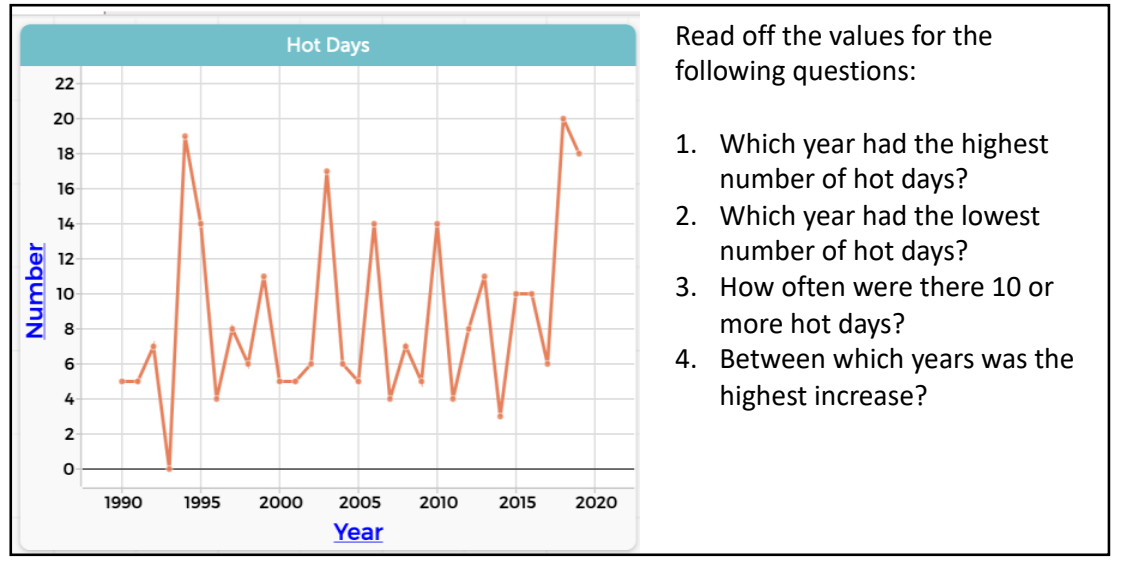

Figure 3. The activity of abstracting is elicited to familiarize the students with line charts 


\subsection{ANALYZING THE CONFLICT}

The course then proceeded to the analysis phase of the Resolving Conflicting Information design principle. The Incomplete Information regarding the model from the earlier phase is now partly completed by the given line chart (see Figure 4).

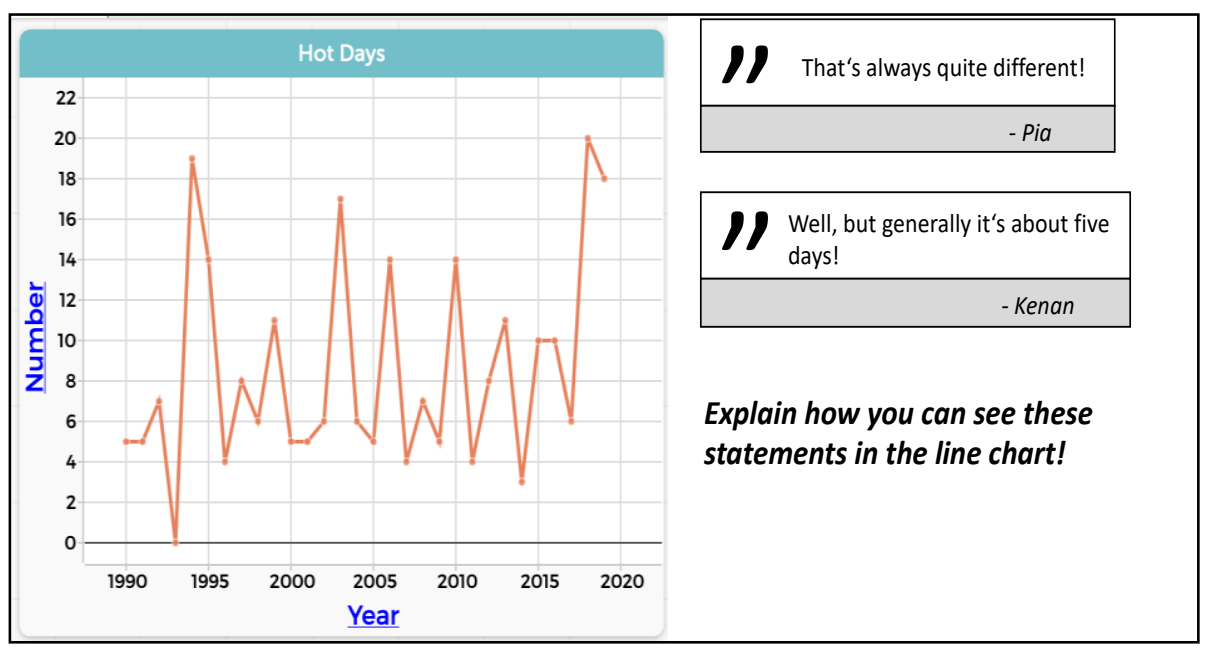

Figure 4. The conflict is partly analyzed with the help of a line chart (translated from German)

Here, the students were asked to explain how the line chart was interpreted in one of the comments made by Pia and Keenan. This again led to imaginative reading of arguments:

S1 The line chart fits to Pia's statement, because the days always were so different.

S2 Well, the line of the line chart is not so steady, meaning that the line has quite a lot of swerves.

Similar to the first answers, Student 1 provided a very general answer, whereas Student 2 made explicit the features of the model of the line chart that related to the argument that the weather was very different. She introduced the "swerves" of the line, effectively finding a model with the line chart that corresponded to the "differences" used earlier. This is an example of de-interpreting, as Student 2 explicitly found the features of the model that were possibly the basis of Kenan's argument. It is also notable that neither student explained whether Kenan's argument fit this model. A central tendency would be very hard to observe directly given this line chart. It is possible the students recognized this, but had difficulties explicating the relationship between the model and the argument - a sign that the conflict needs further analysis.

To provide additional models to help in the analysis of the conflict, the course then introduced dot plots to the students, giving them a step-by-step procedure for constructing dot plots in CODAP. Dot plots were very likely to be new to the students, as they are not yet included in German curriculum standards. The decision to incorporate them was made because they provide opportunities for intuitive reasoning about center and variability. As before, the students were asked to construct a dot plot and answer a few questions (see Figure 5). These questions were intended to familiarize students with dot plots as well as to show that some questions are more easily answered with dot plots than with line charts and vice versa. 


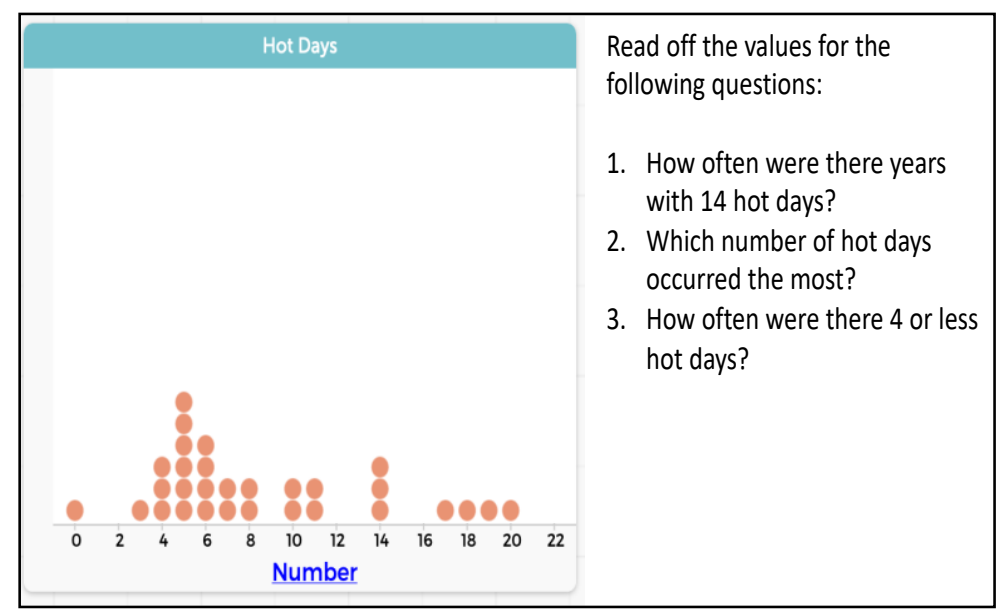

Figure 5. The activity of abstracting is elicited to familiarize the students with dot plots (translated from German)

Afterwards, the students were asked to relate Kenan's argument to the dot plot (see Figure 6). Here, the missing information was completed as the model underlying Kenan's argument was made available. Discussing the ways in which the dot plot fits Kenan's argument again elicits activities of interpreting and de-interpreting. Both students provided similar explanations of the fit of the dot plot to the argument, focusing on 5 as the mode of the number of hot days, while also acknowledging the variability around the mode ("around" 5 days):

S1 The statement fits to the dot plot, because most years have around 5 days.

S2 Because there are quite many years in which there are 5 days. And above or below the 5 are also a lot of dots.

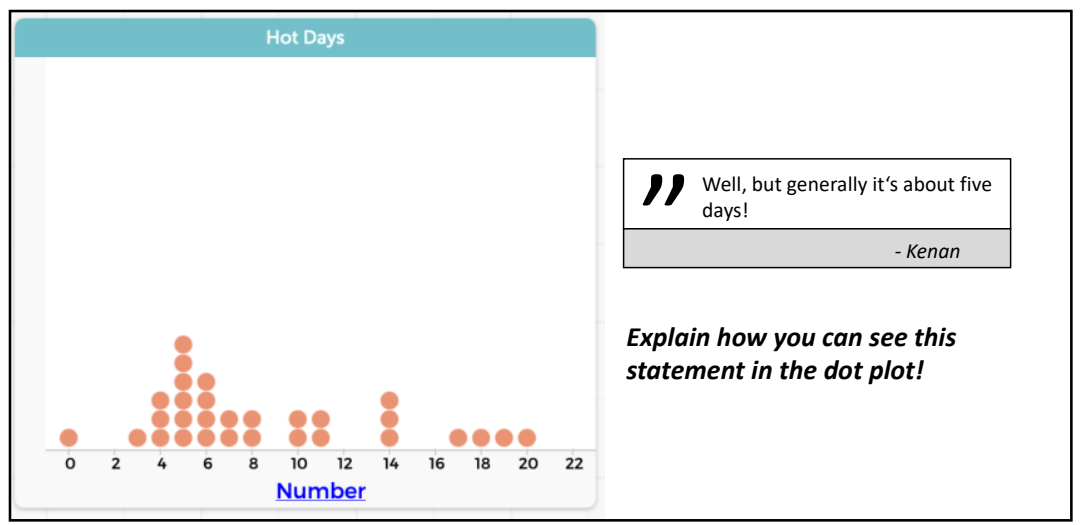

Figure 6. The conflict is further analyzed with the help of a dot plot (translated from German)

\subsection{RESOLVING THE CONFLICT}

After the tools of line charts and dot plots were introduced and the students had the opportunity to experience their uses and limitations, the lesson turned towards the final phase in the Resolving Conflicting Information design principle. This was signaled by an increase in generality, as the general ideas behind line charts and dot plots were made explicit (see Figure 7). 


\begin{tabular}{|c|}
\hline $\begin{array}{c}\text { Dot plots show the frequency of temperatures, } \\
\text { but not their course. }\end{array}$ \\
\hline Explain what that means!
\end{tabular}

Figure 7. The conflict is resolved by organizing the experiences with dot plot and line chart (translated from German)

In the phase of resolving the conflict, the focus on de-interpreting from the previous tasks was now changed to a focus on de-abstracting. To answer the question, the students had to acknowledge two important features in the temperature data. The first feature is that temperatures do tend to cluster around a certain value and looking at how often a certain temperature occurs is an interesting question in the context. The second feature is that temperatures change, they have a trend, and that, too, is an interesting focus. In responding, the students' answers show they were de-abstracting from the model. In the data, there is information regarding an association between year and number of hot days. The students acknowledged that this information is missing from the dot plot.

S1 It means that you can only see the frequency, but not in which year that was.

S2 Probably they mean that you cannot see in the dot plot in which year, for example, there were 5 hot days.

The final task of the lesson again shifted the focus to the de-coding of the temperature data. The students were provided with a different kind of argument by Pia and Kenan: the models and data are not suitable for investigating the phenomenon of climate change (see Figure 8). This changed the focus of investigation. Instead of reasoning about data from the period of 1990 to 2019, the question became whether the data actually encode the phenomenon, or whether different data would be needed.

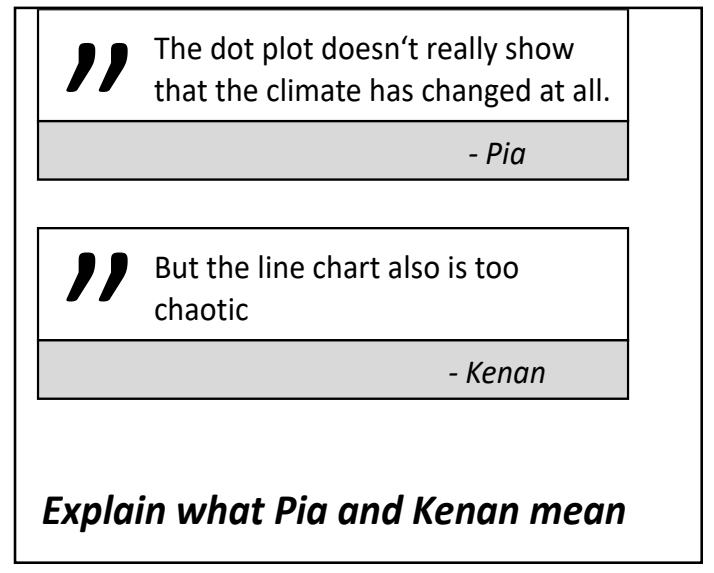

Figure 8: Reflection takes place, prompting activities of de-coding the data (translated from German)

The students respoded by saying:

S1 Pia means that the dot plot is only good for seeing the frequency. Kenan means that the line chart is only good for the trends.

S2 Pia means that you cannot see whether the number of hot days, for example, has increased the whole time. Kenan means that the line chart was uneven anyway.

This task shows how the change to de-coding the data by relating it to the phenomenon seems to be difficult for the students. Student 1 again provided an answer relating data and models, mostly repeating the observations made in the previous task. Student 2 engaged in the intended activity of de-coding. Regarding the phenomenon in this Critical Context, it is important to know whether the number of hot 
days has steadily increased for a longer period than given in the data here. Neither dot plot nor line chart can provide the necessary insights for this.

\subsection{SUMMARY: THE EFFECTS OF THE DESIGN PRINCIPLES}

The teaching unit illustrated here was designed to elicit activities of imaginative reading. It did so by implementing the design principles of Resolving Conflicting Information, Incomplete Information, Critical Contexts, and Digital Tools. Figure 9 provides an overview of how these design principles elicited activities of selective and imaginative reading by showing the activities along with the numbered tasks that elicited the activities. Three of the tasks implemented addressed de-interpreting, either by hypothesizing about possible models behind unclear arguments due to Incomplete Information, or by asking the students to explain the fit between an argument and a model. Other activities of imaginative reading were elicited in the later phase of Resolving Conflicting Information, as the uses and limitations of the dot plot were related to the questions and the data were evaluated regarding whether they in fact allowed investigation of Critical Contexts such as climate change. This was made possible because Digital Tools lowered the demands of producing the statistical representations. It can also be seen that activities of selective reading were not the focus of the teaching unit, as they only appeared when the students were asked to familiarize themselves with reading values off the graphical representations created.

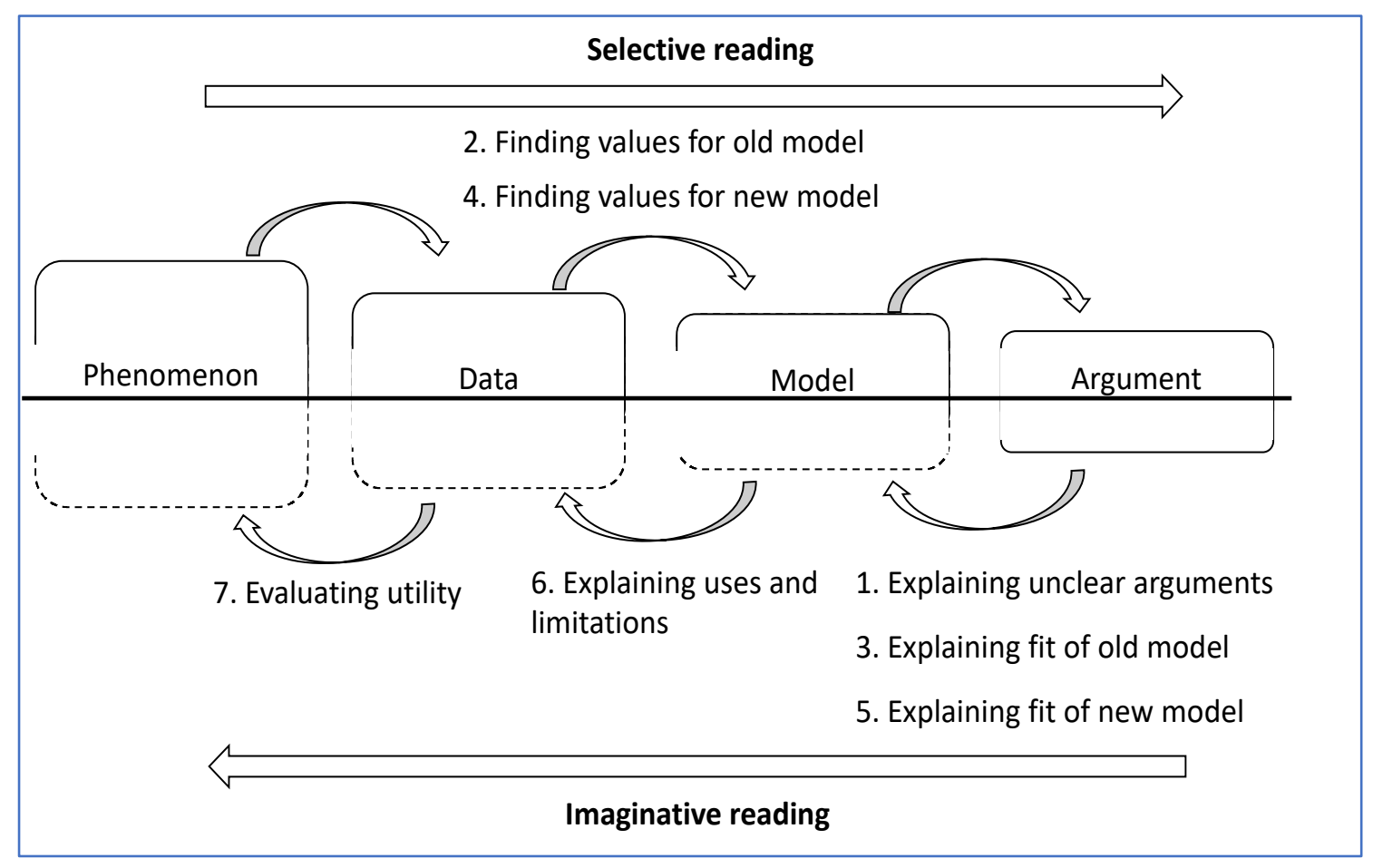

Figure 9. The design principles elicit activities of selective and imaginative reading

All of the first five tasks revolved around the Incomplete Information regarding a missing model. In the first task, students hypothesized about the model by explaining unclear arguments, a deinterpreting activity of imaginative reading. In the second task, the students abstracted data to a model by finding the values for the old model - an activity of selective reading. The progression of activities then alternated between imaginative and selective reading concerning the model. This order of tasks might be considered unusual, as statistics learning trajectories often start with engaging students in reasoning about a phenomenon and engaging in statistical thinking from there. Instead, the progression of tasks of this teaching unit started with de-interpreting statistical arguments and placed the role of the model in the center. Thus, the order of activities reflected the aim of the teaching unit by focusing on 
the statistical literacy necessary to engage with statistical arguments that are presented to the reader without much further information.

It is also clear that many activities important for statistical literacy were not addressed by the design of this teaching unit. As outlined in the theoretical background, activities of selective reading are important for statistical literacy. Critical reflections on the relationship between phenomena and datahow the data were collected, how that influenced the results, and whether the 30-year data provided here allowed for inferences to be made about the climate - only occurred at the very end of the lesson. The claim is not that every lesson has to address every activity. If statistical literacy is to be developed in classrooms with limited resources, instruction has to partition the construct into manageable chunks that can be the object of focused development. The theoretical model of the activities of selective and imaginative reading was constructed with exactly this goal in mind: to differentiate the learning goals of statistical literacy, to provide a theoretical framework for analyzing the contribution of design principles to statistical literacy, and to allow the design of focused didactic materials by focusing on specific activities.

\subsection{OUTLOOK: DESIGNING A FULL LEARNING TRAJECTORY}

In this paper, I described only one teaching unit developed by the cli.math project. Although some activities of selective and imaginative reading could be elicited, they can only be seen as the first step of a full learning trajectory towards statistical literacy. The learning trajectory developed here is displayed in Table 1. It encompasses six teaching units. Each teaching unit integrates a Critical Context and is structured through the Resolving Conflicting Information design principle: (1) the students observe a conflict of information, (2) the students use new statistical concepts to analyze the source of the conflict, and (3) the conflict is resolved by explaining why both pieces of information are selective readings of the same data. This can only be considered an hypothesis, and further empirical research regarding the efficiency of this learning trajectory is required.

Table 1. The learning trajectory implements the Resolving Conflicting Information design principle for different conflicts

\begin{tabular}{|c|c|c|c|c|}
\hline Unit & Context & (1) Conflict & (2) Analysis & (3) Resolution \\
\hline 1 & $\begin{array}{l}\text { Hot days in } \\
\text { Münster } \\
(1990-2019)\end{array}$ & $\begin{array}{l}\text { Weather is chaotic vs. } \\
\text { weather shows patterns. }\end{array}$ & $\begin{array}{l}\text { Line charts show } \\
\text { variability in time series, } \\
\text { dot plots show patterns in } \\
\text { frequencies. }\end{array}$ & $\begin{array}{l}\text { Whether time series or } \\
\text { frequencies are more } \\
\text { important has to be } \\
\text { decided in context. }\end{array}$ \\
\hline 2 & $\begin{array}{l}\text { Hot days in } \\
\text { Münster } \\
(1990-2019)\end{array}$ & $\begin{array}{l}\text { The pattern has } \\
\text { changed vs. the pattern } \\
\text { remains stable. }\end{array}$ & $\begin{array}{l}\text { The mean shows a stable } \\
\text { center, the range shows } \\
\text { increased spread. }\end{array}$ & $\begin{array}{l}\text { Center and spread are } \\
\text { both important for } \\
\text { getting the full picture. }\end{array}$ \\
\hline 3 & $\begin{array}{l}\text { Hot days in } \\
\text { Düsseldorf } \\
(1980-2019)\end{array}$ & $\begin{array}{l}\text { The climate has become } \\
\text { hotter vs. the climate } \\
\text { has stayed the same. }\end{array}$ & $\begin{array}{l}\text { Range and mean remain } \\
\text { stable, quartiles show } \\
\text { increase of hotter years. }\end{array}$ & $\begin{array}{l}\text { Spread can be } \\
\text { investigated through } \\
\text { different measures. }\end{array}$ \\
\hline 4 & $\begin{array}{l}\text { Arctic sea ice } \\
\text { extent } \\
(1982-2012)\end{array}$ & $\begin{array}{l}\text { The ice is stable vs. the } \\
\text { ice has decreased } \\
\text { significantly. }\end{array}$ & $\begin{array}{l}\text { Median and maximum } \\
\text { remain relatively stable, } \\
\text { minimum has dropped } \\
\text { dramatically. }\end{array}$ & $\begin{array}{l}\text { The importance of } \\
\text { measures depends on } \\
\text { the context. }\end{array}$ \\
\hline 5 & \multicolumn{4}{|c|}{ Introduction of box plots } \\
\hline 6 & $\begin{array}{l}\text { Arctic sea ice } \\
\text { extent } \\
(1982-2012)\end{array}$ & $\begin{array}{l}\text { Dot plots are best vs. } \\
\text { box plots are best. }\end{array}$ & $\begin{array}{l}\text { Dot plots show all data, } \\
\text { box plots provide } \\
\text { summaries. }\end{array}$ & $\begin{array}{l}\text { Revealing patterns } \\
\text { sometimes requires } \\
\text { loss of information. }\end{array}$ \\
\hline
\end{tabular}

\section{CONCLUSION}

As data become increasingly influential on modern society, statistical literacy becomes ever more important (Wild, 2017). Research in statistics education has provided sophisticated conceptualizations 
of what it means to be a statistically literate citizen in the modern age (Engel, 2017; Gal, 2002; Weiland, 2017; Wild, 2017). Researchers have also begun to find ways to develop the statistical literacy of students, but mostly in later stages of education (Budgett \& Rose, 2017; Jones \& Goldring, 2017). This paper extends this work through two contributions: elaborating a specification of the learning content of statistical literacy; and identifying design principles for developing statistical literacy in middle schools that may be transferable to many different school contexts.

Design research work often requires a careful restructuring of the learning content (Hußmann \& Prediger, 2016), which provides the major theoretical work of a study. This study conceptualized statistical literacy in a way that integrates the two roles of data producer and data consumer (Weiland, 2017). In keeping with the theme of literacy, this study considers the data-producing side of statistical literacy as selective reading, during which phenomena are transformed into data, data into models, and models into statistical arguments. Each of these activities of selective reading enhances the clarity of message, but also results in a loss of information. In order to judge the validity of a statistical argument, a data consumer has to take this loss of possibly critical information into account. Thus, an imaginative reading needs to be carried out, hypothesizing about the model behind the statistical argument, about the data behind the model, and about the phenomenon behind the data. The activities of selective and imaginative reading, namely encoding and decoding, de-abstracting, and de-interpreting, thus provide a specification of the learning content of statistical literacy.

Several design principles were identified that can support the development of statistical literacy in middle schools. The design principle of Resolving Conflicting Information provides a framework for the design of tasks consisting of three subsequent steps: (1) conflicting statistical information about a single phenomenon is introduced, (2) the information is analyzed through selective and imaginative reading, and (3) the conflict is resolved by finding its source in the different selective readings produced through the statistical information. The design principle of Incomplete Information supports elicitations of imaginative reading by purposefully omitting important information regarding some statistical information. This prompts students to search for possible explanations behind the perceived conflicting information. This is supported by the design principle of Critical Contexts, which states that socially relevant contexts such as climate change can elicit the search for possible explanations of the conflict. Finally, the design principle of Digital Tools reduces the demands of manually creating statistical representations, which allows an increased focus on reflecting the available statistical information.

The results illustrated here demonstrate the feasibility of the identified design principles, but further research is still necessary for investigating their effects. The two students who provided the illustrations here did so on two different levels, with Student 2 providing more sophisticated answers than Student 1. This raises the question of the type of support students like Student 1 might need. Because prior knowledge was not controlled and only the written answers were evaluated, this study does not provide answers to that question. Further studies could investigate the conditions for the success of the design principles by controlling prior knowledge or by investigating the learning processes at a micro level. It would also require more studies to investigate whether the design principles are productive for other areas of statistical literacy, in other school contexts, or for other statistical learning content. Finally, additional aspects of statistical literacy were not focused on here, such as knowledge of why and how data are gathered and stored (Gould, 2017).

Statistical literacy is a complex construct with great importance to society. As this could threaten to overwhelm designers of didactic materials, Wild (2017) calls for the identification of small lessons of statistical literacy that can provide the focus for instruction. This paper has illustrated one such small lesson that addressed the issue that over the course of selective reading, information gets lost through the activities of encoding, abstracting, and interpreting. Focusing on reversing these activities through imaginative reading has the potential to allow designers of didactic materials to create learning opportunities specifically for statistical literacy.

\section{REFERENCES}

Arnold, P., Confrey, J., Jones, R. S., Lee, H. S., \& Pfannkuch, M. (2018). Statistics learning trajectories. In D. Ben-Zvi, K. Makar, \& J. Garfield (Eds.), International handbook of research in statistics education (pp. 295-326). Springer. https://doi.org/10.1007/978-3-319-66195-7_9 
Bakker, A., \& Gravemeijer, K. P. E. (2004). Learning to reason about distribution. In D. Ben-Zvi \& J. Garfield (Eds.), The challenge of developing statistical literacy, reasoning and thinking (pp. 147168). Springer. https://doi.org/10.1007/1-4020-2278-6_7

Bakker, A., \& van Eerde, D. (2015). An introduction to design-based research with an example from statistics education. In A. Bikner-Ahsbahs, C. Knipping, \& N. Presmeg (Eds.), Approaches to qualitative research in mathematics education (pp. 429-466). Springer. https://doi.org/10.1007/978-94-017-9181-6_16

Ben-Zvi, D., \& Garfield, J. (Eds.) (2004). The challenge of developing statistical literacy, reasoning and thinking. Springer. https://doi.org/10.1007/1-4020-2278-6

Ben-Zvi, D., Gravemeijer, K., \& Ainley, J. (2018). Design of statistics learning environments. In D. Ben-Zvi, K. Makar, \& J. Garfield (Eds.), International handbook of research in statistics education (pp. 473-502). Springer. https://doi.org/10.1007/978-3-319-66195-7_16

Biehler, R., Ben-Zvi, D., Bakker, A., \& Makar, K. (2013). Technology for enhancing statistical reasoning at the school level. In M. A. Clements, A. Bishop, C. Keitel, J. Kilpatrick, \& F. Leung (Eds.), Third international handbook of mathematics education (pp. 643-690). Springer. https://doi.org/10.1007/978-1-4614-4684-2_21

Budgett, S., \& Rose, D. (2017). Developing statistical literacy in the final school year. Statistics Education Research Journal, 16(1), 139-162. https://doi.org/10.52041/serj.v16i1.221

Büscher, C. (2018). Mathematical literacy on statistical measures: A design research study. Springer. https://doi.org/10.1007/978-3-658-23069-2

Büscher, C., \& Prediger, S. (2019). Students' reflective concepts when reflecting on statistical measures: A design research study. Journal Für Mathematik-Didaktik, 40(2), 197-225. https://doi.org/10.1007/s13138-019-00142-2

Callingham, R., \& Watson, J. M. (2017). The development of statistical literacy at school. Statistics Education Research Journal, 16(1), 181-201. https://doi.org/10.52041/serj.v16i1.223

Carmichael, C., Callingham, R., Watson, J., \& Hay, I. (2009). Factors influencing the development of middle school students' interest in statistical literacy. Statistics Education Research Journal, 8(1), 62-81. https://iase-web.org/documents/SERJ/SERJ8(1)_Carmichael.pdf?1402525008

Clements, D. H., \& Sarama, J. (2004). Learning trajectories in mathematics education. Mathematical Thinking and Learning, 6(2), 81-89. https://doi.org/10.1207/s15327833mt10602_1

Concord Consortium. (2021). CODAP: Common Online Data Analysis Platform. https://codap.concord.org/

Deutscher Wetterdienst (n.d.). Klimadaten Deutschland. Retrieved from https://www.dwd.de/DE/leistungen/klimadatendeutschland/klimadatendeutschland.html

Douady, R. (1985). The interplay between different settings. Tool-object dialectic in the extension of mathematical ability. In L. Streefland (Ed.), Proceedings of the ninth international conference for the psychology of mathematics education (Vol. 2, pp. 33-52). IGPME.

Engel, J. (2017). Statistical literacy for active citizenship: A call for data science education. Statistics Education Research Journal, 16(2), 44-49. https://doi.org/10.52041/serj.v16i1.213

François, K., Monteiro, C., \& Allo, P. (2020). Big-data literacy as a new vocation for statistical literacy. Statistics Education Research Journal, 19(1), 194-205. https://doi.org/10.52041/serj.v19i1.130

Gal, I. (2002). Adults' statistical literacy: Meanings, components, responsibilities. International Statistical Review, 70(1), 1-25. https://doi.org/10.2307/1403713

Gould, R. (2017). Data literacy is statistical literacy. Statistics Education Research Journal, 16(1), $22-$ 25. https://doi.org/10.52041/serj.v16i1.209

Grant, R. (2017). Statistical literacy in the data science workplace. Statistics Education Research Journal, 16(1), 17-21. https://doi.org/10.52041/serj.v16i1.207

Hußmann, S., \& Prediger, S. (2016). Specifying and structuring mathematical topics. Journal Für Mathematik-Didaktik, 37(S1), 33-67. https://doi.org/10.1007/s13138-016-0102-8

Jones, J. S., \& Goldring, J. E. (2017). Telling stories, landing planes and getting them moving: A holistic approach to developing students' statistical literacy. Statistics Education Research Journal, 16(1), 102-119. https://doi.org/10.52041/serj.v16i1.219

Krishnan, S. (2015). Fostering students' statistical literacy through significant learning experience. Journal of Research in Mathematics Education, 4(3), 259. https://doi.org/10.17583/redimat.2015.1332 
Lehrer, R., \& English, L. (2018). Introducing children to modeling variability. In D. Ben-Zvi, K. Makar, \& J. Garfield (Eds.), International handbook of research in statistics education (pp. 229-260). Springer. https://doi.org/10.1007/978-3-319-66195-7_7

Lesh, R., \& Lehrer, R. (2003). Models and modeling perspectives on the development of students and teachers. Mathematical Thinking and Learning, 5(2-3), 109-129. https://doi.org/10.1080/10986065.2003.9679996

Makar, K., Bakker, A., \& Ben-Zvi, D. (2011). The reasoning behind informal statistical inference. Mathematical Thinking and Learning, 13(1-2), 152-173. https://doi.org/10.1080/10986065.2011.538301

Organisation for Economic Co-operation and Development. (2018). Pisa 2022 Mathematics Framework (Draft). https://pisa2022-maths.oecd.org

Peschek, W., \& Schneider, E. (2002). CAS in general mathematics education. ZDM, 34(5), 189-195. https://doi.org/10.1007/BF02655821

Poling, L., \& Weiland, T. (2020). Using an interactive platform to recognize the intersection of social and spatial inequalities. Teaching Statistics, 42(3), 108-116. https://doi.org/10.1111/test.12234

Prediger, S. (2019). Theorizing in design research. Avances De Investigación En Educación Matemática, 15, 5-27. https://doi.org/10.35763/aiem.v0i15.265

Prediger, S., \& Zwetzschler, L. (2013). Topic-specific design research with a focus on learning processes: The case of understanding algebraic equivalence in grade 8. In T. Plomp \& N. Nieveen (Eds.), Educational design research: Part A: An introduction (pp. 409-423). SLO.

Prediger, S., Gravemeijer, K., \& Confrey, J. (2015). Design research with a focus on learning processes: An overview on achievements and challenges. ZDM - Mathemtics Edcuation, 47(6), 877-891. https://doi.org/10.1007/s11858-015-0722-3

Prodromou, T., \& Dunne, T. (2017). Statistical literacy in data revolution era: Building blocks and instructional dilemmas. Statistics Education Research Journal, 16(1), 38-43. https://doi.org/10.52041/serj.v16i1.212

Sabbag, A., Garfield, J., \& Zieffler, A. (2018). Assessing statistical literacy and statistical reasoning: The REALI Instrument. Statistics Education Research Journal, 17(2). 141-160 https://doi.org/10.52041/serj.v17i2.163

Steen, L. A. (Ed.) (2001). Mathematics and democracy: The case for quantitative literacy. National Council on Education and the Disciplines.

van den Akker, J. (1999). Principles and methods of development research. In J. van den Akker, R. M. Branch, K. Gustafson, N. Nieveen, \& T. Plomp (Eds.), Design approaches and tools in education and training (pp. 1-14). Springer. https://doi.org/10.1007/978-94-011-4255-7

Weiland, T. (2017). Problematizing statistical literacy: An intersection of critical and statistical literacies. Educational Studies in Mathematics, 96(1), 33-47. https://doi.org/10.1007/s10649-0179764-5

Weiland, T. (2019). The contextualized situations constructed for the use of statistics by school mathematics textbooks. Statistics Education Research Journal, 18(2), 18-38. https://doi.org/10.52041/serj.v18i2.138

Wild, C. J. (2017). Statistical literacy as the Earth moves. Statistics Education Research Journal, 16(1), 31-37. https://doi.org/10.52041/serj.v16i1.211

Wild, C. J., \& Pfannkuch, M. (1999). Statistical thinking in empirical enquiry. International Statistical Review, 67(3), 223-265.

Yolcu, E. (2014). Middle school students' statistical literacy: Role of grade level and gender. Statistics Education Research Journal, 13(2), 118-131. https://doi.org/10.52041/serj.v13i2.285

Zieffler, A., Garfield, J., \& Fry, E. (2018). What is statistics education? In D. Ben-Zvi, K. Makar, \& J. Garfield (Eds.), International handbook of research in statistics education (pp. 37-70). Springer. https://doi.org/10.1007/978-3-319-66195-7_2

CHRISTIAN BÜSCHER

Institut für Entwicklung und Erforschung des Mathematikunterrichts

TU Dortmund

Vogelpothsweg 87

44227 Dortmund, Germany 